\section{A modified technique of scleral fixated intraocular lenses for aphakic correction}

AL Young ${ }^{1}$, GYS Leung ${ }^{1}$, LL Cheng ${ }^{1,2}$ and

DSC Lam

\begin{abstract}
Purpose To examine the safety and efficacy of a modified scleral fixated intraocular lens (SFIOL) technique combining a scleral tunnel for intraocular lens (IOL) insertion, horizontal passage of sutures, and performing anterior vitrectomy through self-sealing pars plana sclerostomies.
\end{abstract}

Methods Retrospective review of all patients who underwent SFIOL for aphakic correction at the Department of Ophthalmology and Visual Sciences, The Chinese University of Hong Kong, Prince of Wales Hospital, Hong Kong (a tertiary referral centre) between October 2000 and December 2001 with either the modified or conventional techniques. Results A total of 20 eyes were identified. Eight modified (Group 1) and 12 conventional (Group 2) with a mean follow-up of $\mathbf{1 8 . 3}$ months. Postoperatively, all the eyes improved on unaided preoperative acuity and they all had a stable and well-positioned IOL. In all, 85\% (7/8) of eyes in Group 1 maintained or improved best-corrected visual acuity. Conclusions The modified SFIOL technique was found to be as safe and effective as conventional techniques. The main advantages of this technique include easy intraoperative suture management and superior globe maintenance.

Eye (2005) 19, 19-22. doi:10.1038/sj.eye.6701412

Published online 16 April 2004

Keywords: scleral fixation; intraocular lens; aphakia

\section{Introduction}

Intraocular lens (IOL) insertion to correct aphakia offers superior visual rehabilitation in comparison to aphakic spectacles or contact lenses. In the absence of adequate capsular support, anterior chamber lenses, iris fixated lenses and scleral fixated intraocular lens (SFIOL) may be considered. Anterior chamber IOLs are associated with complications such as glaucoma, hyphaema, uveitis, cystoid macula oedema, and corneal decompensation. ${ }^{1,2}$ SFIOL is an accepted alternative, but has its own associated limitations. ${ }^{3}$

One of the common problems encountered by surgeons performing SFIOL is the tendency for globe collapse during the procedure. The maintenance of globe integrity is particularly difficult in eyes with low scleral rigidity and small palpebral fissures (eg oriental eyes). This problem is further accentuated in cases performed under local anaesthetics. Another common inconvenience is suture entanglement around the ends of the IOL haptics.

In order to obviate the above two problems, we have devised a modified technique in using scleral tunnel, sutureless sclerostomies pars plana anterior vitrectomy (PPAV), and ab externo four point fixation of IOL by direct horizontal passage of sutures. Scleral tunnel incisions offer superior globe maintenance in comparison to one-plane limbal or corneal incisions. The various advantages offered by PPAV with its superb intraocular pressure (IOP) maintenance during anterior vitrectomy (AV) have been described. ${ }^{4-7}$ The simple systematic placement of sutures facilitates smooth knot rotation and burial within the eye. In this paper, we set out to evaluate the safety and efficacy of this modified SFIOL technique. In addition, the outcome of cases performed with the modified technique would be compared with conventional SFIOL procedures.

\section{Materials and methods}

All patients presented with inadequate capsular support who received single SFIOL for aphakic
${ }^{1}$ Department of

Ophthalmology and Visual Sciences

The Chinese University of Hong Kong

Prince of Wales Hospital Shatin, N.T. Hong Kong

People's Republic of China

${ }^{2}$ Alice Ho Miu Ling Nethersole Hospital Tai Po N.T. Hong Kong People's Republic of China

Correspondence: AL Young Department of

Ophthalmology and Visual Sciences

The Chinese University of Hong Kong Prince of Wales Hospital Shatin, Hong Kong Tel: + 8685226322878

Fax: + 8685226482943

E-mail: asmyoung@

netvigator.com

Received: 22 October 2003 Accepted in revised form: 6 January 2004 Published online: 16 April 2004

Financial and proprietary Interest: Nil

Financial support: Supported in part by Action For Vision (AFV) Eye Foundation, Hong Kong 
correction (between October 2000 and December 2001) at a tertiary referral centre were reviewed. The patients underwent either the modified PPAV technique or 'conventional' AV.

All patients had full preoperative evaluation including refraction, BSCVA, IOP, specular microscopy, slit-lamp, and fundal examination. The patient records were reviewed for intraoperative and postoperative complications and visual outcome. The statistical analyses for the two groups were carried out using Student's $t$-test.

\section{Modified SFIOL technique}

All of the modified SFIOL operations were performed by one of the two authors (ALY or DSCL). A superior fornixbased conjunctival flap was fashioned by radial incisions at 3 and 9 clock hours. A gentle impression was made in the centre of the cornea by the blunt end of a Sinski hook (no ink markings to obscure the central sacrificial view). The four entry sites for the SFIOL sutures and needles were marked by ink $-2 \mathrm{~mm}$ behind the limbus and $2 \mathrm{~mm}$ apart. An $8 \mathrm{~mm}$ scleral tunnel was prepared (care taken not to enter inadvertently) followed by the construction of two sutureless sclerostomies for PPAV at 2 and 10 clock hours. ${ }^{4}$ Radial scleral tunnels of $1.5 \mathrm{~mm}$ in length were prepared, starting about $5 \mathrm{~mm}$ posterior to the limbus and advancing forward till $3.5 \mathrm{~mm}$ from limbus. Following $\mathrm{AV}$, the anterior chamber was entered through the scleral tunnel. A 27-G bent needle was then inserted through ' $a$ ' to receive the straight needle of a double ended $10 / 0$ polypropylene suture passed horizontally through ' $b$ ' (Figure 1). The needles were inserted perpendicularly through the sclera and then passed horizontally along the posterior iris plane (aiming to avoid the vascular ciliary body).

The suture was then fished out through the scleral tunnel with a Sinski hook, cut, and allowed to lie laterally on both sides at ' $\mathrm{e}$ ' and ' $\mathrm{f}$ '. The same procedure was repeated as above in the opposite directions - 27-G bent needle through ' $c$ ' and the other arm of the 10.0 polypropylene straight needle through ' $\mathrm{d}$ ' for the two lower sclerostomies. The suture was again fished out from the scleral tunnel with a Sinski hook, cut, and placed at ' $\mathrm{g}$ ' and ' $\mathrm{h}$ ' between the two cut ends originating from the superior sclerostomies. A closed suture loop for both the eyelets (one piece PMMA IOL, CZ70BD, Alcon International, USA) was created by feeding the right side stitch from below up through the eyelet (ie $f$ and g) to meet the respective end (ie $\mathrm{h}$ and e) and tied. After the knots were freely retrieved out of the eye on both sides of the eye, the IOL was inserted with care (special attention was paid to keep the polypropylene suture taut in avoiding any haptic entanglement). Temporary knots

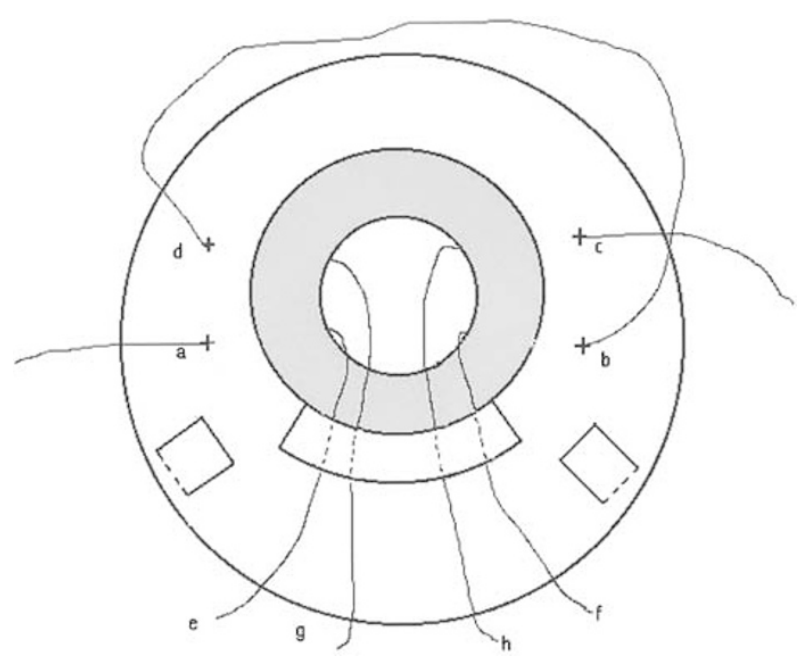

Figure 1 The intraoperative placement and position of polypropylene sutures (surgeon's view).

were tied after checking for free rotation of the sutures. This was followed by closure of the scleral tunnel with interrupted 10.0 nylon as required. The sclerostomies for PPAV were checked for any leakage or vitreous. The eye was rechecked and reformed to normal tension. The sutures of the two ends of the SFIOL were securely tied and the knots were rotated and buried. Conjunctiva closure was achieved by 8.0 polyglactin sutures.

The main modifications of this technique include the usage of a scleral tunnel, the direct horizontal passage of needle and systematic positioning of suture, and the application of PPAV. For the 'conventional' AV cases performed by other experienced surgeons, either one plane corneal or limbal wounds were used. The AV was performed through the same wounds (not PPAV) and $a b$ externo fixation techniques were used.

\section{Results}

A total of 20 eyes were identified for this study. Eight eyes received the modified technique (Group 1), while 12 eyes received the conventional technique (Group 2). Table 1 presents a summary of the demographic data of the patients. The two groups were similar for age and follow-up period. Table 2 shows a summary of the clinical data of the patients. There were no statistical differences between the two groups for pre- and postoperative refraction, visual acuity, and specular microscopic endothelial counts.

There were no irreversible visually significant complications in any of the patients. There were five cases of mild vitreous haemorrhage (from sclerostomy suture sites) and two cases of small choroidal detachment. All these subsequently resolved without sequelae. None of the sclerostomy sites for PPAV 
Table 1 Summary of the demographic data of patients

\begin{tabular}{|c|c|c|c|c|}
\hline & $\begin{array}{r}\text { Group } 1 \\
n=8\end{array}$ & $\begin{array}{c}\text { Group } 2 \\
\mathrm{n}=12\end{array}$ & $\begin{array}{c}\text { Combined } \\
\mathrm{n}=20\end{array}$ & $P$ value \\
\hline Mean age (years) & $71.75 \pm 8.65$ & $62.25 \pm 26.46$ & $66.05 \pm 21.35$ & 0.267 \\
\hline Age range (years) & $54-81$ & $14-86$ & $14-86$ & \\
\hline Mean FU duration (months) & $21.75 \pm 2.31$ & $16 \pm 6.24$ & $18.30 \pm 6$ & 0.023 \\
\hline \multicolumn{5}{|l|}{ Sex } \\
\hline Male & $4(50.0 \%)$ & $8(66.6 \%)$ & $12(60 \%)$ & \\
\hline Female & $4(50.0 \%)$ & $4(33.3 \%)$ & $8(40 \%)$ & \\
\hline \multicolumn{5}{|l|}{ Laterality } \\
\hline Left & $6(75.0 \%)$ & $6(50 \%)$ & 12 & \\
\hline Right & $2(25.0 \%)$ & $6(50 \%)$ & 8 & \\
\hline
\end{tabular}

Table 2 Summary of the pre- and postoperative data of the patients

\begin{tabular}{lccrr}
\hline & $\begin{array}{c}\text { Group 1 } \\
\mathrm{n}=8\end{array}$ & $\begin{array}{c}\text { Group 2 } \\
\mathrm{n}=12\end{array}$ & $\begin{array}{c}\text { Combined } \\
\mathrm{n}=20\end{array}$ & $\begin{array}{c}\text { P value } \\
\text { Mean preoperative VA (Log MAR) }\end{array}$ \\
Mean preoperative BSCVA (Log MAR) & $1.7125 \pm 0.54$ & $1.75 \pm 0.36$ & $1.738 \pm 0.43$ & 0.833 \\
Mean pre-op refraction (SE) & $0.35 \pm 0.17$ & $0.532 \pm 0.49$ & $0.459 \pm 0.34$ & 0.332 \\
Mean preoperative endothelial count (cells $/ \mathrm{mm}^{2}$ ) & $10.09 \pm 2.64$ & $10.56 \pm 6.65$ & $10.37 \pm 5.51$ & 0.854 \\
Mean postoperative BSCVA (Log MAR) & $2418 \pm 1002$ & $1823 \pm 402$ & $2061 \pm 743$ & 0.079 \\
Mean post-op refraction (SE) & $0.288 \pm 0.0855$ & $0.423 \pm 0.36$ & $0.369 \pm 0.29$ & 0.312 \\
\hline
\end{tabular}

required any suturing. There were no cases of postoperative retinal detachment. Furthermore, there were no cases of suture (kinking, erosion, and exposure), vitreous (incarceration or herniation), and $\mathrm{IOL}^{8}$ (malposition or iris capture) related complications.

A total of four patients (20\%) suffered a loss of BSCVA after surgery (One (12.5\%) in Group 1 and three (25\%) in Group 2). Two of the eyes could be explained by atrophic maculopathy. One patient was known to have tight sutures but defaulted follow up for further management. One patient was noted to have a pale disc with a known background of previous phacomorphic glaucoma prior to surgery.

\section{Discussion}

SFIOL has been used in both adults and children with success, either as a single procedure or combined with penetrating keratoplasty and other vitreoretinal procedures. ${ }^{3,8-11}$ There are many variations of the technique and a range of complications of varying frequencies, which include suture and knot erosions, lens tilt, dislocation or decentration, infection, glaucoma, cystoid macula oedema, corneal decompensation, retinal detachment, and suprachoroidal haemorrhage. ${ }^{3,8-15}$

The maintenance of ocular tension and the avoidance of globe collapse would be technically demanding in cases with low scleral rigidity, small palpebral fissures (eg oriental eyes), poor exposure, and high vitreous pressure. In addition, sutures tied improperly would induce torque and tilt of IOL and erosion if not rotated or buried. ${ }^{16}$ Our modified technique was found to be safe and effective in counteracting these two inconveniences. The induced torque on one side of the IOL was counteracted by sutures tied in opposite directions on the other side.

The creation of a scleral tunnel was found to offer much better ocular stability in comparison to conventional one plane limbal or corneal incisions. The eyes were much less likely to suffer from the marked fluctuations of IOP and anterior chamber depth that can occur during SFIOL, particularly when instruments were introduced or withdrawn in and out of the eye. Globe integrity was excellent during $\mathrm{PPAV}^{4-7}$ as the procedure was effectively performed in a closed chamber. In addition, a more thorough vitrectomy could be performed in areas not easily accessible from conventional corneal or limbal wounds, for example, subincisional areas and internal areas of the sclerostomies. There were no cases of leakage or vitreous incarceration in our series.

The simple and systematic schema for the placement and tying of sutures was found to be most satisfactory. The schema is easy to remember as the same side stitch is to be used in the same direction for both haptic eyelets of the IOL (ie the right suture to be fed from below up). As a 
result, we did not have any problems with suture entanglement, failure to rotate and bury, and IOL malposition. ${ }^{16}$

The main limitation of this study would be the small sample size. Nevertheless, the modified technique was comparable to conventional techniques for safety and for this series, a higher percentage of visual improvement. However, the modified technique may not be suitable in cases with significant conjunctiva scarring or previous filtration surgery. In addition, PPAV may not be familiar to traditional anterior segment surgery and training would be needed to master the required skills.

In conclusion, we have found the modified technique for SFIOL to be safe and effective. The main variations of this technique are the use of scleral tunnel, PPAV, and the schema for the passage and tying of suture. This technique allows for superior intraoperative globe maintenance and suture management.

\section{References}

1 Apple DJ, Mamalis N, Loftfield K, Googe JM, Novak LC, Kavka-Van Norman D et al. Complications of intraocular lenses: a historical and histopathological review. Surv Ophthalmol 1984; 29: 1-54.

2 Smith PW, Wong SK, Stark WJ, Gottsch JD, Terry AC, Bonham RD. Complications of semiflexible, closed-loop anterior chamber intraocular lenses. Arch Ophthalmol 1987; 105: 52-57.

3 Uthoff D, Teichmann KD. Secondary implantation of scleralfixated intraocular lenses. J Cataract Refract Surg 1998; 24: 945-950.

4 Chen JC. Sutureless pars plana vitrectomy through selfsealing sclerotomies. Arch Ophthalmol 1996; 114: 1273-1275.
5 Rahman R, Rosen PH, Riddell C, Towler H. Self-sealing sclerotomies for sutureless pars plana vitrectomy. Ophthalmic Surg Lasers 2000; 31: 462-466.

6 Kwok AK, Tham CC, Lam DS, Li M, Chen JC. Modified sutureless sclerotomis in pars plana vitrectomy. $A m \mathrm{~J}$ Ophthalmol 1999; 127: 731-733.

7 Lam DS, Chua JK, Leung AT, Fan DS, Ng JS, Rao SK. Sutureless pars plana anterior vitrectomy through selfsealing sclerotomies in children. Arch Ophthalmol 2000; 118: 850-851.

8 Lam DS, Ng JS, Fan DS, Chua JK, Leung AT, Tham CC. Short term results of scleral intraocular lens fixation in children. J Cataract Refract Surg 1998; 24: 1474-1479.

9 Zetterstrom C Lundvall A, Weeber Jr H, Jeeves M. Sulcus fixation without capsular support in children. J Cataract Refract Surg 1999; 25: 776-781.

10 Johnston RL, Charteris DG. Pars plana vitrectomy and sutured posterior chamber lens implantation. Curr Opin Ophthalmol 2001; 12: 216-221.

11 Walter KA, Wood TD, Ford JG, Winnicki J, Tyler ME, Reed JW. Retrospective analysis of a novel method of transscleral suture fixation for posterior-chamber intraocular lens implantation in the absence of capsular support. Cornea 1998; 17: 262-266.

12 Bleckmann H, Kaczmarek U. Functional results of posterior chamber lens implantation with scleral fixation. J Cataract Refract Surg 1994; 20: 321-326.

13 Price Jr FW, Wellemeyer M. Transcleral fixation of posterior chamber intraocular lenses. J Cataract Refract Surg 1995; 21: 567-573.

14 McCluskey P, Harrisberg B. Long term results using scleralfixated posterior chamber intraocular lenses. J Cataract Refract Surg 1994; 20: 34-39.

15 Solomon K, Gussler JR, Gussler C, Meter WSV. Incidence and management of complications of transsclerally sutured posterior chamber lenses. J Cataract Refract Surg 1993; 19: 488-493.

16 Teichmann KD, Teichmann IA. The torque and tilt gamble. J Cataract Refract Surg 1997; 23: 413-418. 